\title{
Congenital lobar emphysema: problems in diagnosis and management
}

\author{
D W K MAN, M H HAMDY, G M A HENDRY, W H BISSET, AND J O FORFAR \\ Departments of Paediatric Surgery, Radiology, and Child Life and Health, Royal Hospital for Sick Children, \\ Edinburgh
}

SUMMARY A retrospective study was made of 9 patients with congenital lobar emphysema who presented over the past 13 years. The ages of the patients at diagnosis ranged from 2 weeks to 10 years. The earlier the presentation, the more severe were the symptoms. Two patients were misdiagnosed initially at the referring hospitals with near disastrous results. Pitfalls in diagnosis are outlined and the various investigative procedures discussed. A flow chart for the diagnostic approach is presented. Treatment was usually by lobectomy but 2 older children presenting late with mild symptoms were managed conservatively with satisfactory results.

Since the first report on the successful treatment of lobar emphysema by lobectomy by Gross ${ }^{1}$ in 1945 , several series ${ }^{2-4}$ have been reported indicating increased awareness of this condition. Even today, despite modern technology, pitfalls in diagnosis and treatment are still common. Congenital lobar emphysema may present in different forms varying from an acute neonatal respiratory emergency to recurrent attacks of respiratory embarrassment or chest infection in the older child. This may be confusing to the clinician faced with the problem of diagnosing this rare condition from a large variety of common acquired respiratory problems in children. We review our clinical experience with congenital lobar emphysema during the past 13 years and seek to delineate the salient features with particular reference to clinical diagnosis, investigative techniques, methods of treatment, and common problems related to management.

\section{Clinical material}

Nine patients with congenital lobar emphysema ( 5 boys and 4 girls) were diagnosed between 1970 and 1982 at this hospital and at Ismailia General Hospital, Egypt. Their ages at diagnosis ranged from 2 weeks to 10 years. Presentation, management, and progress are detailed in the Table.

Table Presentation, management, and progress in 9 patients with congenital lobar emphysema

\begin{tabular}{|c|c|c|c|c|c|}
\hline Case No. & $\operatorname{Sex}$ & Age & Presenting feature & Treatment & Progress \\
\hline$* 1$ & $\mathbf{M}$ & 2 days & $\begin{array}{l}\text { Respiratory distress, iatrogenic } \\
\text { pneumothorax }\end{array}$ & Left upper lobectomy & Well at 1 month postoperative \\
\hline 2 & $\mathbf{F}$ & 5 days & Tachypnoea and cyanosis & Right lower lobectomy & $\begin{array}{l}\text { Occasional URTI, PDA divided } \\
18 \text { months }\end{array}$ \\
\hline 3 & $\mathbf{M}$ & 2 months & Wheeze and cough & Left upper lobectomy & $\begin{array}{l}\text { Occasional wheeze, asthma at } \\
2 \text { years age }\end{array}$ \\
\hline 4 & $\mathbf{F}$ & 2 months & Wheeze and cough & Right middle lobectomy & $\begin{array}{l}\text { Occasional wheeze, well at } \\
8 \text { years age }\end{array}$ \\
\hline 5 & $\mathbf{M}$ & 4 months & Wheeze and cough & Left upper lobectomy & $\begin{array}{l}\text { Delayed development, chronic } \\
\text { granulomatous disease }\end{array}$ \\
\hline 6 & $\mathbf{M}$ & 4 months & Recurrent chest infections & Left upper lobectomy & $\begin{array}{l}\text { Normal development, no chest } \\
\text { problems at } 16 \text { months post- } \\
\text { operative }\end{array}$ \\
\hline$* 7$ & $\mathbf{F}$ & 6 months & $\begin{array}{l}\text { Tachypnoea, cough and fever; } \\
\text { iatrogenic tension pneumothorax }\end{array}$ & Left upper lobectomy & $\begin{array}{l}\text { Thriving at } 12 \text { months } \\
\text { postoperative }\end{array}$ \\
\hline 8 & $\mathbf{M}$ & 7 years & Wheeze & Not operated on & $\begin{array}{l}\text { Occasional chest pain after } \\
\text { exercise }\end{array}$ \\
\hline *9 & $\mathbf{F}$ & 10 years & $\begin{array}{l}\text { Cough: chest infection at } 4 \text { years } \\
\text { with collapse of LLL }\end{array}$ & Not operated on & Well \\
\hline
\end{tabular}

*See case reports.

URTI = Upper respiratory tract infection; PDA = patent ductus arteriosus; LLL = Left lower lobe. 
The affected site was the left upper lobe in 6 patients, the right middle lobe in 1, the right lower lobe in 1, and the left lower lobe in 1. In all patients the classic signs of decrease in air entry, increased percussion resonance, and decreased vocal fremitus over the affected lobe were eventually found. Tracheal deviation was evident in all except the 2 older children who had very mild symptoms. Lobectomy was carried out in 7 of the 9 patients and histological examination of the resected lobe and bronchus in these 7 did not show any specific aetiological factor.

\section{Case reports}

Patient 1. A $2.01 \mathrm{~kg}$ boy (Table, case 1) was delivered at another hospital at 32 weeks' gestation. The Apgar score was 9 at both 1 and 5 minutes. He was tachypnoeic and was treated for respiratory distress syndrome. At 1 week a chest radiograph showed increased translucency over the left hemithorax. On day 16 he was severely distressed with marked indrawing. A further chest radiograph was interpreted as showing left sided pneumothorax. A chest drain was inserted on several occasions, each time with no drainage of air and no improvement of the clinical condition. The patient was transferred to this hospital for further management. On admission a chest radiograph showed a small left pneumothorax-probably iatrogenic, together with left upper lobar emphysema. The diagnosis was confirmed at emergency left thoracotomy and left upper lobectomy was performed. By the second day after operation the left lower lobe had fully expanded to occupy the left hemithorax (Fig. 1). Recovery was smooth and he was discharged from hospital 3 weeks after operation.

Patient 2. A 6 month old girl (Table, case 7) presented at the Ismailia General Hospital, Egypt with a 4 day history of cough, fever, and tachypnoea. She had had 2 similar attacks at 3 and 4 months of age, both treated with antibiotics. Chest radiograph showed a translucent area in the left upper zone herniating across the midline through the anterior mediastinum. An infected solitary lung bulla was diagnosed and diagnostic aspiration of the 'bulla' was performed. Tension pneumothorax developed with a marked increase in the respiratory distress with cyanosis. The baby suffered cardiac arrest but was immediately resuscitated and a left chest drain inserted with clinical improvement. On review of chest radiographs a diagnosis of congenital obstructive emphysema affecting the left upper lobe was made and left upper lobectomy was performed. She made an uneventful recovery from the operation and was discharged from hospital on the 10th postoperative day. At follow up 1 year later she was thriving with no chest problems.

Patient 3. A 4 year old girl (Table, case 9) was treated in another hospital for cough and fever. Chest radiograph showed collapse of the left lower lobe with emphysema of the left upper lobe thought

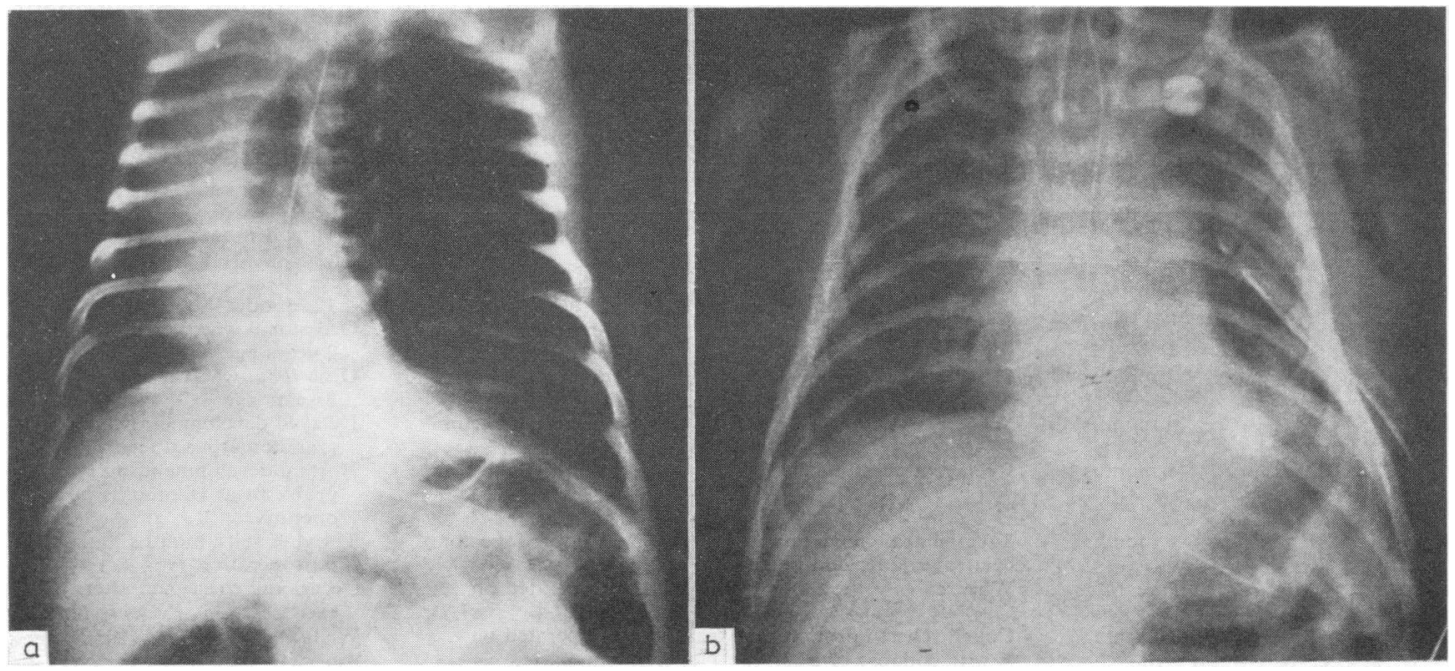

Fig. 1 (a) Chest radiograph showing congenital obstructive emphysema affecting the left upper lobe. This appearance was mistakenly interpreted as 'pneumothorax'. (b) Chest radiograph 2 days after left upper lobectomy. 
to be compensatory in nature. The emphysema persisted at 4 months after recovery but she was lost to follow up. She was well until she came under medical care again at the age of 10 years when she developed a cough which lasted for 7 weeks. Chest radiograph again showed the presence of left upper lobar emphysema. Fluoroscopy showed that the mediastinum moved to the left on inspiration and to the right on expiration, indicating an obstructive emphysema. Her plasma $\alpha_{1}$ antitrypsin value was normal and elective bronchoscopy did not reveal any specific findings. Bronchography showed filling of the anterior and lingular segmental bronchi in the left upper lobe but these segments were depressed inferiorly by an emphysematous apical segment. In view of the mild symptoms it was decided that no further investigation was warranted. She was still well and asymptomatic at the age of 13 years.

\section{Discussion}

Congenital lobar emphysema varies in presentation. The onset of symptoms is usually in early infancy and is uncommon after 6 months of age, but this series varied from 2 days to 7 years of age. The earlier the presentation, the more severe the symptoms. The 2 neonates presented with fairly severe respiratory distress. Two of the 5 infants presented with chest infection and the other 3 presented with wheeze and cough. In the latter patients, it would be difficult to tell whether wheezing and coughing were symptoms of the obstructive emphysema or an upper respiratory infection that then brought to light the underlying condition. The older children presented with very mild symptoms and were otherwise healthy and well.

The clinical diagnosis of congenital lobar emphysema may be difficult. Plain chest radiograph with anterior-posterior and lateral views gives vital information. The characteristic appearance is that of pressure expansion of a lobe of lung causing compression of adjacent lobes. The vascular supply to the emphysematous lobe is poor. ${ }^{5}{ }^{6}$ There is widening of the rib spaces and depression of the diaphragm on the affected side. The mediastinum may be displaced away from the emphysematous side. In severe cases the overexpanded lung may herniate into the contralateral hemithorax. The lobes commonly affected are the left upper, right upper, and right middle lobes. These radiological features together with the clinical picture of a neonate or infant in respiratory distress may be diagnostic of congenital lobar emphysema and further investigation is unnecessary. The condition should not be misdiagnosed as pneumothorax or lung bulla. Attempts to aspirate the 'lung bulla' in the patient in case 7 of this series proved disastrous and nearly fatal. Insertion of a chest drain for 'pneumothorax' in the patient in case 1 resulted in an iatrogenic pneumothorax with deterioration in the child's condition. These mistakes may be avoided by careful observation of the chest radiograph which in cases of congenital lobar emphysema usually shows bronchovascular markings in the radiolucent area.

When the condition occurs in an older child with less severe clinical signs or when there are atypical radiological features, compensatory emphysema and other causes of non-obstructive emphysema should be considered. Fluoroscopy in these patients helps to establish the diagnosis. In obstructive emphysema fluoroscopy shows shifting of the mediastinum towards the emphysematous side on inspiration and away from it on expiration, poor diaphragmatic movement on the affected side, and a lack of volume change of the emphysematous lobe with respiration.

In most cases the diagnosis may be established by plain chest radiograph and screening of the chest. Lung isotope scanning using ${ }^{81 \mathrm{~m}} \mathrm{Kr}$ ventilation and ${ }^{99 \mathrm{~m} T c}$ macroaggregates perfusion shows a matched $\mathrm{V} / \mathrm{Q}$ abnormality in the affected lobe. ${ }^{7}$ Ventilation/perfusion scanning will show a normal lung in cases of compensatory emphysema and help diagnose the underlying abnormality in adjacent lung tissue such as hypoplasia or aplasia in the contralateral lung and underperfusion in cases of collapse/consolidation in the ipsilateral lung. ${ }^{8}$ In children with bullas from lung infections or congenital causes, lung scanning may show other areas of abnormal $\mathrm{V} / \mathrm{Q}$ unsuspected on the plain chest radiograph. When other causes of obstructive emphysema are suspected, barium swallow may exclude extrinsic compression to a bronchus such as abberant vessels or bronchogenic cysts. Bronchography in selected cases will identify the obstructed bronchus whether lobar or segmental and show either an intrinsic or extrinsic obstruction. It must be noted, however, that this investigative procedure is not indicated and may be dangerous in the neonate with respiratory distress. In this series bronchoscopy with a rigid bronchoscope was not useful in the diagnosis but we did not have experience with a flexible fibreoptic bronchoscope. Bronchoscopy may, however, rule out foreign bodies as the cause of obstruction particularly in older children. More invasive investigative procedures such as arteriography may be required occasionally to show anomalous vessels causing extrinsic compression to a bronchus. ${ }^{910}$ A flow chart showing the use of the various diagnostic investigations is set out in Fig. 2. 


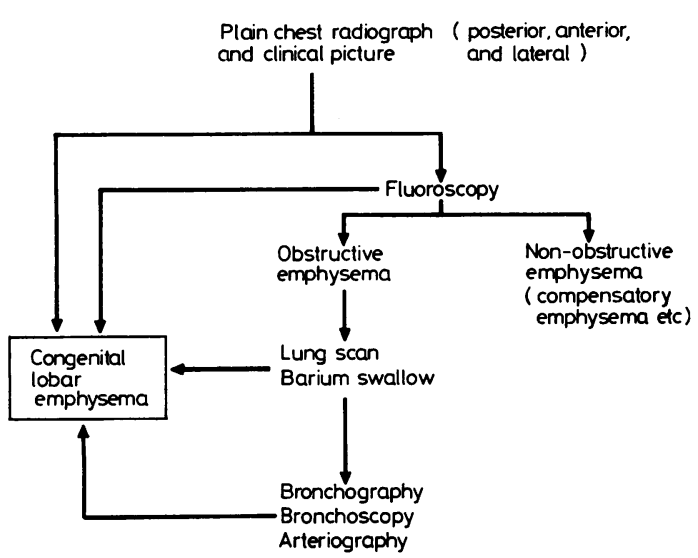

Fig. 2 Diagnostic approach for congenital lobar emphysema.

Treatment of congenital lobar emphysema with serious symptoms is usually by lobectomy. In neonates and infants with severe respiratory distress emergency thoracotomy may be lifesaving. Even under anaesthesia it is important not to ventilate the patient until the chest is opened and the overdistended spongy emphysematous lobe is delivered into the wound. For less acute cases, elective lobectomy may be performed under more favourable conditions. Although the emphysema may affect only a segment of a lobe, segmental resection is not recommended because of higher postoperative complication rates. In older children with mild symptoms, however, lobectomy may not be indicated. Eigen et al.11 found that lung growth and function in a small group of children with congenital lobar emphysema treated conservatively were no different from that of children treated surgically by lobectomy. Our 2 patients who had no operation fared very well. A conservative policy of management in these cases is justified.

\section{References}

1 Gross RE, Lewis JE, Jr. Defect of anterior mediastinum. Successful surgical repair. Surg Gynecol Obstet 1945;80: 549-54.

2 Murray GF. Congenital lobar emphysema. Surg Gynecol Obstet 1967;124:611-25.

3 Lincoln JCR, Stark J, Subramanian S, et al. Congenital lobar emphysema. Ann Surg 1971 ;173:55-62.

4 Binet JP, Langlois J, Belloy A, et al. Traitement chirurgical des emphysèmes pulmonaires malformatifs du nourrisson (à propos de 56 cas opérés). Ann Chir Infant 1972;13:59-64.

5 Hendren WH, McKee DM. Lobar emphysema of infancy. J Pediatr Surg 1966;1:24-39.

- Kennedy JH, Rothman BF. The surgical treatment of congenital lobar emphysema. Surg Gynecol Obstet $1965 ; 121: 253-60$.

7 Mitnick JS, Kutin NS, Braunstein P, Sanger J. Radioisotope evaluation of congenital lobar emphysema. Clin Nucl Med $1981 ; 6: 266-7$.

8 Mauney FM, Jr, Sabiston DC. The role of pulmonary scanning in the diagnosis of congenital lobar emphysema. Amer Surg 1970;36:20-7.

- Contro S, Miller RA, White H, Potts, WJ. Bronchial obstruction due to pulmonary artery anomalies. I: vascular sling. Circulation 1958;17:418-23.

10 Potts WJ, Holinger PH, Rosenblum AH. Anamalous left pulmonary artery causing obstruction to right main bronchus. Report of a case. JAMA 1954;155:1409-11.

11 Eigen H, Lemen RJ, Waring WW. Congenital lobaremphysema: long-term evaluation of surgical and conservatively treated children. Am Rev Respir Dis 1976;113:823-31.

Correspondence to Mr David W K Man, FRCS, Hospital for Sick Children, Great Ormond Street, WCIN 3JH.

Received 12 May 1983 